\section{Systemic changes in the elderly patient and their anaesthetic implications}

Henri Desmeules MD FRCP(C),

Louis Fournier MD FRCP(C),

Paul-René Tremblay MD FRCP(C)
The most recent statistics in the United States show that 11 per cent of the population is over 65 years of age and that this percentage will reach 12.5 per cent in the year $2000 .^{1,2}$ After the age of 65 , over half the population will require a surgical intervention. ${ }^{3}$ The Canadian statistics are probably comparable.

The risks of surgery and general anaesthesia are increased in the elderly patient. In one report, the incidence of morbidity after elective surgery under general anaesthesia was 4.88 per cent in patients over 65 years of age as compared with 0.75 per cent in younger patients. ${ }^{4}$ In emergency surgery, the mortality rate is about ten per cent in elderly patients. ${ }^{5}$ It is therefore essential that the anaesthetist be aware of the systemic changes related to aging and their anaesthetic implications.

Before beginning this short review, it is important to emphasize that chronological age should be distinguished from physiological age. Thus the definition of the geriatric patient as being anyone over 65 years of age is arbitrary.

\section{Cardiovascular system}

In aging there is a progressive increase in cardiac volume due to an increased peripheral resistance causing left ventricular hypertrophy. ${ }^{6}$ The myocardium and conducting system are subject to fibrosis, the valves calcify, the coronary arteries lose their elasticity, diminish in calibre and become atherosclerotic. ${ }^{7,8}$ Other vessel walls undergo a similar structural deterioration, becoming progressively less compliant.

These anatomical and histological changes of the cardiovascular system are accompanied by functional modifications. Cardiac output progressively decreases in elderly patients and may be as much as 40 per cent less than in young adults. This reduced cardiac output is caused by both decreased ejection volume and heart rate. The maximum heart rate response to exercise is reduced ${ }^{3.9}$ The circulation time is prolonged. ${ }^{5}$ Diminished arterial elasticity leads to a progressive increase in blood pressure, especially the systolic component. These age related modifications cause a significant reduction in cardiac reserve. A decreased responsiveness of the autonomic nervous system favours stress-related cardiac decompensation. ${ }^{10}$

Age-related cardiovascular changes eventually lead to pathologic processes that may cause sudden and lethal complications during anaesthesia. The most frequent cardiovascular abnormalities in elderly patients include arterial hypertension, coronary insufficiency, valvular lesions, conduction defects, arrhythmias and the carotid sinus syndrome."

Arterial hypertension and hypokalemia, which may be a treatment side-effect, should be satisfactorily controlled before anaesthesia. ${ }^{12}$ Elderly patients often have labile blood pressure during anaesthesia. Conduction defects and arrhythmias can cause a sudden reduction in cardiac output because of poor cardiac reserve. ${ }^{13}$ Arrhythmias should be evaluated and controlled preoperatively and patients with heart block may need to have a pacemaker inserted.

Patients in congestive cardiac failure or with coronary insufficiency should be evaluated and stabilized before undergoing anaesthesia. Operative mortality is particularly high in this group of patients. ${ }^{14}$ Elective anaesthesia should not be

From the Department of Anesthesia, Faculty of Medicine, Laval University.

Address correspondence to: Dr. Henri Desmeules, Department of Anesthesia, Centre hospitalier de l'Université Laval, 2705, boul. Laurier, Sainte-Foy, Québec, G1V 4G2. 
undertaken during the three- to six-month period following myocardial infarction. ${ }^{15,16}$

\section{Respiratory system}

Progressively diminishing respiratory function in the elderly patient is a major handicap with respect to general anaesthesia. The age-related anatomical and functional changes which are frequently accompanied by lung disease result in a decreased pulmonary reserve.

Aging is associated with decreased thoracic expansion, diminished lung elasticity, reduced alveolar surface and weakened respiratory muscles. ${ }^{17,18}$ These changes lead to small airway closure which is associated with a decreased vital capacity, an increased functional residual capacity and residual volume. ${ }^{19,20}$ The maximal breathing capacity, the total lung capacity and the vital capacity are reduced. ${ }^{21}$ Decreased responsiveness to hypercapnia and hypoxia are frequently seen in elderly patients. ${ }^{22}$

Most elderly patients are hypoxemic. The arterial $\mathrm{PO}_{2}$ decreases by an average of 0.5 torr each year after the age of $20 .^{23}$ The alveolo-arterial oxygen gradient increases from 8 to 20 tor between age 20 and 70 years. Many factors contribute to the inefficient arterial oxygenation in the elderly patient, including altered ventilation-perfusion ratios, decreased pulmonary surface, decreased membrane permeability and decreased capillary blood volume. $^{3}$

The age-related pulmonary function changes are often associated with various lung pathology. Obstructive lung disease is the most common pulmonary abnormality found in elderly patients and has a male predominance. These patients are prone to respiratory infections which are a frequent cause of postoperative death. Protective upper airway reflexes decrease with age leaving elderly patients susceptible to bronchial aspiration. ${ }^{24}$

Functional lung deterioration associated with lung pathology may predispose elderly patients to postoperative respiratory failure. Preoperative evaluation of respiratory function in elderly patients should include the determination of expiratory volumes and flow rates and arterial blood gases. If pulmonary resection is contemplated a more complete evaluation will be required. ${ }^{25}$ In the presence of significant anomalies elective anaesthesia must be deferred and adequate treatment initiated. In the postoperative phase many elderly patients will require ventilatory support in a specialized unit.

\section{Nervous system}

Aging leads to progressive functional and structural changes in the nervous system. The average weight of the brain in adults is $1400 \mathrm{~g}$. It falls to $1150 \mathrm{~g}$ at 80 years of age due to decreased number of neurones, especially in the cerebral and cerebellar cortex ${ }^{26,27}$ In nerve axons, there is loss of myelin, reduction of synapses and a diminished number of fibres in tracts.

In the elderly, there is a decrease in the rate of synthesis and an increase in the rate of destruction of neurotransmitter substances. ${ }^{28}$ These alterations may be associated with behaviour modification, memory problems and confusion in elderly patients. Muscles and neuromuscular function deteriorate with age. There are fewer motor units and each axon innervates fewer muscle fibres. This in turn may lead to eventual denervation and muscle atrophy. ${ }^{3}$ Changes in the central nervous system produce a decrease in anaesthetic and analgesic drug requirement. ${ }^{5}$ The minimum alveolar concentration of volatile agents (MAC) diminishes sharply with age. ${ }^{29}$ MAC for halothane decreases by approximately 25 per cent between the ages of 20 and 80 years. ${ }^{29}$ The decrease in MAC for isoflurane between the ages of 26 and 64 years is about 18 per cent. ${ }^{30}$ Neuromuscular alterations lead to increased myorelaxant sensitivity. ${ }^{3}$

The most frequent neurological diseases seen in the elderly patient include cerebrovascular insufficiency, Parkinson's disease and peripheral neuropathies. Regional anaesthesia may be contraindicated in elderly patients with mental confusion and peripheral neuropathies. After general anaesthesia elderly patients are prone to transitory psychologic and EEG modifications. ${ }^{31}$ Patients with Parkinson's disease who have been receiving L-Dopa may have arrhythmias, hypotension and thoracic cage rigidity during anaesthesia. ${ }^{32}$

\section{Renal and hepatic systems}

Renal blood flow diminishes progressively with age to reach 40 to 50 per cent of the normal value at age $65 .^{33}$ Glomerular filtration, renal concentration and renal acidification are also decreased. ${ }^{34}$ There is a reduction in the number of glomerules. Some tubules atrophy, others hypertrophy. ${ }^{35}$ Renal re- 
serve being diminished, the elderly patient is more susceptible to circulatory overload, dehydration and electrolyte imbalance during anaesthesia. ${ }^{11}$ In addition many drugs are less well eliminated by the aging kidney. ${ }^{36}$ These drugs include gallamine, pancuronium, digoxin, cimetidine, lithium, procainamide, chlorpropamide and the most commonly used antimicrobial agents. ${ }^{11,36,37}$

Decreased cardiac output in the elderly patient leads to a proportional reduction in hepatic blood flow. This is reflected by a progressive increase in BSP retention after 40 years of age. ${ }^{38}$ Microsomal enzyme activity is also reduced. ${ }^{36}$ Drugs metabolised by the liver have therefore longer half-lives and prolonged actions. In addition, elderly patients are at risk with respect to hepatotoxic drugs. The aging liver also poorly tolerates hypoxia and hypotension.

\section{Metabolic processes and endocrine system}

After the age of 30 years, the basal metabolic rate decreases by one per cent per year. ${ }^{8}$ Muscle tissue decreases and fatty tissue increases. ${ }^{36}$ Hypothermia is frequently noted during and after anaesthesia in the elderly patient. ${ }^{39}$ Thus body temperature should be monitored during the operative and postoperative period and precautions should be taken to prevent hypothermia.

The most frequent endocrine problem encountered in patients over 65 years of age is diabetes mellitus. Insulin liberation is slow in response to hyperglycemia." Preoperative diabetic evaluation and control is mandatory. The objective is to avoid hypoglycemia, ketoacidosis and hyperosmolar states in the perioperative period. Blood glucose should be obtained at the start of the operation and every four hours for the rest of the first 24-hour period. The infusion rate of dextrose and the insulin dosage should be adjusted accordingly. ${ }^{40}$ The use of a portable monitoring apparatus for blood glucose facilitates the management of the diabetic patient during the intraoperative period.

\section{Skeletal system and the skin}

Osteoporosis and arthritis are the lot of the elderly. These patients should be mobilized gently and the head maintained in the neutral position to avoid compromising vertebral artery blood flow. ${ }^{41}$

Compression points should be protected in elderly patients to eliminate skin trauma and nerve compression. ${ }^{42}$ Heating mattresses should be used with care to prevent burns. In aging, facial shape is altered by alveolar bone resorption and loss of dentition leading to concave cheeks. Because of these changes it may be difficult to ventilate adequately an elderly patient by mask due to significant air leakage. The use of an oropharyngeal airway may partially restore the shape of the face and alleviate this problem.

\section{Conclusion}

The administration of anaesthesia to an elderly patient presents a challenge to the anaesthetist. A thorough knowledge of the systemic changes associated with aging is mandatory if the risk of anaesthesia is to be reduced in these patients. Because of their lowered systemic reserves, the elderly require an anaesthetic management based on scientific knowledge, skill, constant surveillance and anticipation.

\section{References}

1 Schneider EL, Butler RN. Geriatrics. JAMA 1981; 245: 2190-1.

2 Thompson TL, Moran MG, Nies AS. Psychotropic drug use in the elderly. N Engl J Med 1983; 308: 134-8.

3 Miller RD. Anesthesia for the elderly. In: Miller RD, ed. Anesthesia. New York: Churchill Livingstone, 1981.

4 Hospital Mortality: PAS Hospital, United States 1974-1975. Ann Arbor, MI. Commission on Professional and Hospital Activitics, 1977.

5 Zamost $B$ and Benumof $J L$. Anesthesia in the geriatric patient. In: Katz J, Kadis LB. Anesthesia and Uncommon Disease. Philadelphia: WB Saunders, 1981 .

6 Lakatla EG. Alterations in the cardiovascular system that occur in advanced aged. Fed Proc 1979; 38: 163-7.

7 Harris $R$. Cardiac changes with age. In: Goldman R, Rockstein M, Eds. Physiology and Pathology of Human Aging. New York: Academic Press, 1975.

8 Evans TI. The physiological basis of geriatric general anesthesia. Anaesth Intensive Care 1973; 1: $319-22$

9 Coath A. Physiologic processes of aging in the cardiovascular system. In: Kretchel SW, ed. Anesthesia and the geriatric patient. Orlando: Grune \& Stratton, 1984. 
10 Kennedy RD, Claird FI. Physiology of aging of the heart. Cardiovasc Clin 1981; 12:1-8.

11 Parkhouse I. Anaesthesia in old age. In: Brocklehurst JC, 2 nd ed. Textbook of geriatric medicine and gerontology. London: Churchill Livingstone, 1978.

12 Gibson PW. Preoperative respiratory and cardiovascular assessment in the elderly. In: Kretchel SW, ed. Anesthesia and the geriatric patient. Orlando Grune \& Stratton, 1984.

13 Kuner J, et al. Cardiac arrhythmias during anesthesia. Dis. Chest. 1967; 52: 580-7.

14 Fraser JG, Ramachandran PL, Davis HS. Anesthesia and recent myocardial infarction. JAMA 1967; 199: 318-20.

15 Steen PA, Tinker JH, Tarhan S. Myocardial reinfarction after anesthesia and surgery. JAMA 1978; 239: $2566-70$.

16 Goldman L, Caldera $D L$, Southwick FS, et al. Cardiac risk factors and complications in noncardiac surgery. Medicine 1978; 57: 357-70.

17 Mauderly JL. Effect of age on pulmonary structure and function of immature and adult animals and man. Fed Proe 1979; 38: 173-7.

18 Knudson RJ, Clark DF, Kennedy TC, et al. Effect of aging alone on mechanical properties of the normal adult lung. J Appl Physiol 1977; 43: 1054-62.

19 Leith DE, Mead J. Mechanism determining residual volume of the lungs in normal subjects. J Appl Physiol 1967; 23: 221-7.

20 Minesan G, Sorbini CA, Grassi V. Respiratory function in the aged. Bull Physiopathol Resp 1971 7: 973-1009.

21 Pontoppidan $H$, Geffins B, Lowenstein A. Acute respiratory failure in the adult. $\mathrm{N}$ Engl J Med 1972; 287: 690-8.

22 Kronenberg RS. Drage CW. Attenuation of ventilatory and heart rate responses to hypoxia and hypercapnia with aging in normal men. J Clin Invest 1973; 52: 1812-19.

23 Wahba $W$, Body build and preoperative arterial oxygen tension. Can Anaesth Soc J 1972; 22: 653-8.

24 Pontoppidan $H$, Beecher $H K$. Progressive loss of reflexes in the airway with the advance of age. JAMA 1960; 174: 2209-13.

25 Wahba WM. Influence of aging on lung function. Clinical significance of changes from age twenty. Anesth Analg 1983; 62: 764-76.

26 Lytle $L D$, Altar $A$. Diet, central nervous system, and aging. Fed Proc 1979; 38: 2017-22.
27 Devaney KO, Johnson HA. Neuron loss in the aging visual cortex of man. J Gerontol 1980; 35: 836-41.

28 Muravchick S. Physiologic processes of aging in the central nervous system. In: Kretchel SW, ed. Anesthesia and the geriatric paticnt. Orlando: Grune \& Stratton, 1984.

29 Gregory GA, Eger ET II, Munson ES. The relationship between age and halothane requirement in man. Anesthesiology 1969; 30: 488.

30 Stevens WC, Dolan WM, Gibbons RT, et al. Minimum alveolar concentrations (MAC) of isoflurane with and without nitrous oxide in patients of various age. Anesthesiology 1975; 42: 197-200.

31 Davenport HT. Anaesthesia for the geriatric patient. Can Anaesth Soc J 1983; 30: S51-S55.

32 Goldberg LI. Levodopa and anesthesia. Editorial. Anesthesiology 1971; 34: 1-3.

33 Friedman $S A$, Raizner AE, Rosen $H$, et al. Functional defects in the aging kidney. Ann Intern Med 1972; 76: 41-5.

34 Epstein $M$. Effects of aging in the kidney. Fed Proc 1979; 38: 168-71.

35 McLachlan MSF. The aging kidney. Lancet 1978; 2: 143-6.

36 Greenblatt DJ, Sellers EM, Shader RI. Drug disposition in old age. $\mathrm{N}$ Engl $\mathrm{J}$ Med 1982; 306: 1081-8.

37 Duvaldestin P, Saada J, Berger JL, et al. Pharmacokinetics, pharmacodynamics and dose-response relationship of pancuronium in control and elderly subjects. Anesthesiology 1982; 56: 388-92.

38 Thompsen $E$, William $R$. Effect of age on liver function with particular reference to bromsulphalein excretion. Gut. 1965; 6: 266.

39 Vaughan MS, Vaughan RW, Cork RC. Postoperative hypothermia in adults: relationship of age, anesthesia and shivering to rewarming. Anesth Analg 1981; 60: 746-5I.

40 Roizen MF. Preoperative evaluation of patients with diseases that require special preoperative evaluation and intraoperative management. In: Miller RD, ed. Anesthesia. New York: Churchill Livingstone, 1981.

41 Owens WD. Anesthesia for the geriatric patient. American Society of Anesthesiologists Refresher Course 1983; 228.

42 Janis $K M$. Anesthesia for the geriatric patient. American Society of Anesthesiologists Refresher Course 1978: 115. 